\title{
Diagnostic Accuracy of Fine Needle Aspiration Cytology of Thyroid Pathologies
}

\section{Shova Kunwarl, Barsha Bajracharya ${ }^{2}$, Kavita Karmacharya ${ }^{1}$ and Amar Narayan Shrestha ${ }^{1}$}

${ }^{1}$ Department of Pathology, Nepalese Army Institute of Health Sciences, Shree Birendra Hospital, Chhauni, Kathmandu, Nepal

${ }^{2}$ Department of Dentistry (Oral Pathology), Nepalese Army Institute of Health Sciences, Shree Birendra Hospital, Chhauni, Kathmandu, Nepal

\section{ABSTRACT}

Introduction: Fine needle aspiration cytology is considered as the gold standard for the diagnosis of thyroid nodules. This study aimed to evaluate and compare the accuracy of fine-needle aspiration cytology in the diagnosis of thyroid lesion by comparing it with the corresponding histopathologic diagnosis after thyroidectomy.

Methods: This is a retrospective study conducted over five years at a teaching hospital in Kathmandu. Eighty-nine cases of FNAC of thyroid nodule with subsequent histopathological reports were reviewed. The corresponding reports were compared and the accuracy of FNAC diagnosis was evaluated.

Results: $87 \%$ of the cases were females and the majority of cases were in the age group 41 to 50 years. Among 89 cases, 55 were reported as benign on cytology and 34 were reported as malignant. On histopathological examination, out of 55 cases diagnosed as benign on cytology, 47 cases were diagnosed as benign whereas eight cases were diagnosed as malignant. HPE of 34 cases diagnosed as malignant on cytology showed that 29 were malignant and five were benign. The false-positive rate was $9.6 \%$ and the false-negative rate was $21.6 \%$. The sensitivity was $78.3 \%$ and specificity was $90.3 \%$. The positive predictive value and negative predictive value were $85.2 \%$ and $85.4 \%$ respectively. The accuracy of FNAC in differentiating benign from malignant thyroid lesions was $85.3 \%$.

Conclusions: The findings of this study showed that FNAC is a sensitive method for the diagnosis of a solid thyroid lesion

Key words: FNAC; histopathology; papillary carcinoma thyroid

Correspondence: Shova Kunwar, Department of Pathology, Nepalese Army Institute of Health Sciences, Shree Birendra Hospital, Chhauni, Kathmandu, Nepal. E-mail: skunvar@yahoo.com.

DOI: http://dx.doi.org/10.3126/mjsbh.v19i2.27329

Submitted on: $2020-01-20$

Accepted on: 2020-05-12 


\section{INTRODUCTION}

Fine Needle Aspiration Cytology (FNAC) is a simple, quick, and cost-effective method that is used to sample superficial masses like those found in the neck and is usually performed in the outpatient clinic. It provides a specific diagnosis rapidly with minimal complications. ${ }^{1}$ FNAC for assessment of thyroid cancer was introduced by Martin and Ellis at New-York Memorial Hospital in $1930 .^{2}$ FNAC has become the diagnostic tool of choice for the initial evaluation of thyroid nodule. The routine use of FNAC in the evaluation of thyroid nodules has reduced the number of patients subjected to thyroidectomy for benign thyroid lesions. ${ }^{3}$

Thyroid nodules have become more common these days with prevalence ranging from 4 to $7 \%$ in the general population. ${ }^{4}$ The majority of these nodules are non-neoplastic or benign neoplasms. FNAC is done in cases of thyroid nodules to distinguish benign from malignant lesions. For proper management of thyroid nodules, they are classified as benign, malignant, suspicious, and insufficient for diagnosis. It helps to decide whether to treat thyroid nodules by surgery or not. The introduction of FNAC into the field of thyroid diagnostic tests has reduced unnecessary thyroid surgeries considerably. However, FNAC has some limitation such as specimen inadequacy and inaccurate sampling techniques. ${ }^{5}$

This study was aimed to identify the accuracy of FNAC in differentiating between benign and malignant thyroid lesions by comparing it with subsequent histopathology.

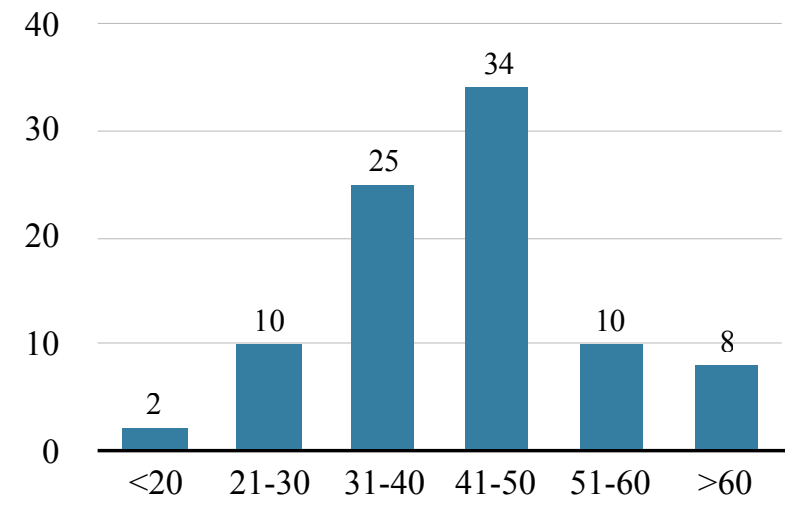

Figure 1. Age distribution in years $(n=89)$

\section{METHODS}

This is a retrospective study carried out at the Department of Pathology, at a teaching institute in Kathmandu, Nepal for five years from August 2013 to November 2018. Cases of FNAC of the thyroid nodule were reviewed. The cytological study was based on an evaluation of FNAC smears. The cytological results were categorised into: benign, suspicious of malignancy, and consistent for malignancy. Unsatisfactory was given if there was only blood and no thyroid follicular cells in cytology. ${ }^{6}$

All the corresponding histopathological reports were then retrieved and reviewed. A total of 89 cases had both cytology and histopathology reports available and were included in the study. Histopathological diagnosis was categorised into categories of benign and malignant. Data were noted and tabulated. Statistical analysis was performed using SPSS version 23. The level of significance was set at 5\%. The statistical analyses include false-positive rate, false-negative rate, sensitivity, specificity, positive predictive value, negative predictive value and accuracy.

\section{RESULTS}

During the study period of five years, 89 cases were included in our study. Most of the patients were in the age group 41 to 50 years (figure 1). $87 \%$ of cases were females and $13 \%$ were males (Figure 2). Among 89 cases, 55 were reported as benign on cytology and 34 were reported as malignant. Of the 55 cases reported as benign on cytology, most were nodular goiter (24\%) followed by Hashimoto's thyroiditis (22\%) (Figure 3). Out of 34 cases diagnosed as malignant on cytology, 19 were consistent for malignancy and 15 were suspicious of malignancy (Table 1).

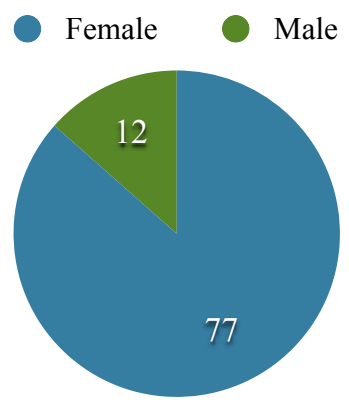

Figure 2. Sex distribution of cases $(n=77)$ 
Follicular lesion

Nodular goiter

Hashimotos thyroiditis

Cystic lesions

Papillary thyroid carcinoma

Medullary carcinoma

Suspicious of malignancy

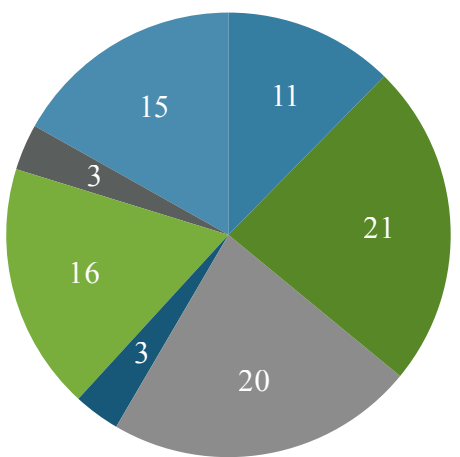

Figure 3. Distribution of FNAC diagnosis $(\mathrm{n}=89)$

On histopathological examination, out of 55 cases diagnosed as benign on cytology, 47 cases were diagnosed as benign whereas eight cases were diagnosed as malignant (table 1). The discordant cases included papillary thyroid carcinoma (PTC) (5), follicular carcinoma (2), and undifferentiated carcinoma (1) (table 2).

HPE of 34 cases diagnosed as malignant on cytology showed that 29 were malignant and five were benign (Table 1). The discordant cases include nodular goiter (3), follicular adenoma (1), and Hashimoto's thyroiditis (1) (table 2).

Statistical analyses were done to find out accuracy of FNA in detecting malignancy in thyroid swelling, which are as follows:

False positive rate $=$ False positive $/$ (False positive + True negative $)=5 /(5+47)=9.6 \%$

False negative rate $=$ False negative $/$ (False negative + True positive $)=8 /(8+29)=21.6 \%$

Sensitivity (probability that a test result will be positive when the disease is present - 'true positive rate')

Sensitivity $=$ True positive / (True positive + False negative $)=29 /(29+8)=78.3 \%$

Specificity (probability that a test result will be negative when the disease is not present - 'true negative rate')
Table 1. Cyto-histopathology correlation of all the cases

\begin{tabular}{|l|c|c|}
\hline \multicolumn{1}{|c|}{ Cytological diagnosis } & $\begin{array}{c}\text { Histopathology } \\
\text { diagnosis }\end{array}$ & $\begin{array}{c}\text { Discordant } \\
\text { cases }\end{array}$ \\
\hline Benign (N=55) & $\begin{array}{c}\text { Benign }(\mathrm{N}=47) \\
{[T N]}\end{array}$ & $\begin{array}{c}8 \\
{[F N]}\end{array}$ \\
\hline $\begin{array}{c}\text { Malignant } \\
(\mathrm{N}=29) \\
{[T P]}\end{array}$ & 5 \\
\hline $\begin{array}{l}\text { Consistent for } \\
\text { malignancy } \\
\begin{array}{l}\text { (N=19) } \\
\text { - Suspicious for }\end{array}\end{array}$ & $\begin{array}{c}\text { Malignant } \\
(\mathrm{N}=18)\end{array}$ & 1 \\
$\begin{array}{l}\text { Malignancy } \\
(\mathrm{N}=15)\end{array}$ & $\begin{array}{c}\text { Malignant } \\
(\mathrm{N}=11)\end{array}$ & 4 \\
\hline
\end{tabular}

$T N=$ True negative, $F N=$ False Negative, $T P=$ True Positive, $\mathrm{FP}=$ False positive

Specificity $=$ True negative $/$ (True negative + False positive $)=47 /(47+5)=90.3 \%$

Positive predictive value (PPV) (probability that the disease is present when the test is positive)

PPV $=$ True positive $/$ (True positive + False positive $)=29 /(29+5)=85.2 \%$

Negative predictive value (NPV) (probability that the disease is not present when the test is negative)

$\mathrm{NPV}=$ True negative / (True negative + False negative $)=47 /(47+8)=85.4 \% \%$

Table 2. Details of the discordant cases

\begin{tabular}{|c|c|c|}
\hline $\begin{array}{c}\text { Number of } \\
\text { Discordant } \\
\text { cases }\end{array}$ & $\begin{array}{l}\text { Cytological } \\
\text { diagnosis }\end{array}$ & $\begin{array}{l}\text { Histopathology } \\
\text { diagnosis }\end{array}$ \\
\hline 9 & Benign & $\begin{array}{l}\text { Malignant } \\
\text { •PTC (5) } \\
\text {-Follicular Carcinoma } \\
\text { (2) } \\
\text {-Undifferentiated } \\
\text { carcinoma (1) }\end{array}$ \\
\hline 1 & $\begin{array}{l}\text { Consistent } \\
\text { for } \\
\text { malignancy }\end{array}$ & $\begin{array}{l}\text { Benign } \\
\cdot \text { Nodular goiter }(1)\end{array}$ \\
\hline 4 & $\begin{array}{l}\text { Suspicious } \\
\text { for } \\
\text { malignancy }\end{array}$ & $\begin{array}{l}\text { Benign } \\
\text { • Nodular goiter (2) } \\
\text { •Follicular adenoma (1) } \\
\text { •Hashimoto's } \\
\text { thyroiditis (1) }\end{array}$ \\
\hline Total $=13$ & & \\
\hline
\end{tabular}


Accuracy is the portion of the correct results, true positive and true negative in relation to all cases studied.

Accuracy $=$ True positive + True negative $/$ total number of cases $=29+47 / 89=85.3 \%$.

Hence, false-positive rate was $9.6 \%$ and the falsenegative rate was $21.6 \%$. The sensitivity was $78.3 \%$ and specificity was $90.3 \%$. The positive predictive value and negative predictive value were $85.2 \%$ and $85.4 \%$ respectively. The accuracy of FNAC in differentiating benign from malignant thyroid lesions was $85.3 \%$.

\section{DISCUSSION}

FNAC is a simple, minimally invasive, and costeffective tool for the initial diagnosis of thyroid nodules. It mainly helps to distinguish between a malignant and benign lesion. FNAC must be accurate because the surgical treatment of thyroid lesions is highly influenced by the FNAC report. Benign lesion of thyroid requires conservative procedures like lobectomy and partial thyroidectomy whereas malignant nodules require aggressive treatment like total thyroidectomy, neck dissection, radioiodine ablation etc. ${ }^{7}$ Since this study was conducted to correlate the accuracy of FNA in detecting benign and malignant lesions, lesions without atypia have been categorised into benign and lesions with atypia has been categorised into consistent with malignancy. Further, suspicious lesions have been grouped into malignant lesions as the treatment of both the suspicious and consistent with malignant lesions are the same. FNAC is a highly sensitive and specific procedure for thyroid lesion, however; the discrepancy may occur, when there is no adequate sample, sample are not from a representative area and technique of sample collection is incorrect. ${ }^{8,9}$

In the present study, thyroid lesions were more predominant in females with a ratio of $3.5: 1$. The majority of patients were in there fourth and fifth decades of life. Study done by Rout $\mathrm{K}$ et al. reported that 53 cases were females and 23 were males with the peak age of incidence was in second and third decades of life. This is similar to our study in the case of the Female to Male ratio but different in case of the age group from the present study. A study by Gupta et al. found that 69 cases were females and six cases were male. ${ }^{10}$ A study carried out by Kumar $S$ et al. also found that thyroid lesions are more common in females with a female: male ratio of 4.2:1.1

In the present study, 55 cases were reported as benign, 19 were malignant and 15 were reported as suspicious for malignancy. Out of 55 cases which were reported as benign, eight cases were malignant in histopathology. Discordant cases were five PTC, two follicular carcinoma, and one undifferentiated carcinoma. Nineteen cases were malignant in FNAC whereas one was nodular goiter in histopathology. Among four suspicious for malignancy in FNAC, four were benign, two were nodular goiter, one was follicular adenoma, and one was Hashimoto's thyroiditis. In study done by Sharma C et al., out of 945 cases, 635 were benign, 68 malignant and 21 suspicious for malignancy in FNAC. Out of 635 cases, nine cases were malignant in histopathology, eight were PTC and one was follicular carcinoma. In 68 malignant cases, two were nodular goiter. In nine suspicious cases, seven were nodular goiter, two were follicular adenoma, and one was Hashimoto's thyroiditis. ${ }^{3}$ The present study has similar discordant cases as a study done by Chetan Sharma et al. ${ }^{3}$

It is important to remember that various classification systems for thyroid FNA reporting are used worldwide, ranging from three to six or more diagnostic categories. The system most commonly used is the Bethesda System, which contains six categories as follows: Non diagnostic or unsatisfactory, benign, lesion (atypia) of undetermined significance, follicular neoplasm or suspicious for follicular neoplasm, suspicious for malignancy and malignant. ${ }^{6}$ The classification system used in this article contains three diagnostic categories: benign, suspicious, and malignant. Since FNAC aims to rule out malignancy, it should have a low false-negative rate, high negative predictive value, and acceptable sensitivity and specificity. So, in this study we have applied all these statistical parameters.

In our study, the false-negative rate was $21.6 \%$. In a similar study conducted by Sinna EA et al., falsenegative rate was $5.8 \% .{ }^{12}$ In a study conducted by Kuru B et al., regarding fine-needle aspiration cytology for diagnosing thyroid carcinoma in thyroid nodules, the false-negative rate was $2 \% .^{13}$ 
The higher false-negative rate in our study may be due to inadequacy in sample collection or aspiration of fluid from cystic areas of underlying malignant lesions. High false negative can result in missing out potential malignant lesions. To prevent this, careful long term clinical follow-up of thyroid lesions is required. ${ }^{14}$

Negative predictive value is the probability the subjects with a negative screening test truly don't have the disease. ${ }^{15}$ In this study, negative predictive value was $85.4 \%$. In a similar study conducted by Sina et al., negative predictive value was $91.8 \% .^{12}$ A study by Muratli et al. in assessing the accuracy of thyroid FNAC in thyroid nodule, the negative predictive value was reported to be $79.5 \%{ }^{16}$

The sensitivity of FNAC of thyroid lesion in our study was $78.3 \%$ and specificity was $90.3 \%$. Various studies have shown a wide range sensitivity of FNAC of thyroid from $65 \%$ to $99 \%$ and its specificity from $72 \%$ to $100 \% .{ }^{14}$ Both the statistical indices of this study are within the range reported by various studies. The reason for this wider range of sensitivity and specificity of different studies can be due to variation in how pathologists handle the category of suspicious and how false positive and false negative results are defined. In the similar study conducted by Sinna et al., sensitivity was 92.8 and specificity was $94.2 \% .^{12}$ Mundasad et al. had done a similar study and founded that FNAC had a sensitivity of $52.6 \%$, specificity of $86.6 \% .^{17}$

Baloch et al. ${ }^{18}$ had done a comparison study between FNAC and histopathology of thyroid lesion and found that the accuracy and FNAC were $91.6 \%$ which is similar to the accuracy calculated in our study $(85.3 \%)$. In a study similar to ours carried out by Handa et al. ${ }^{19}$, FNAC showed sensitivity of $97 \%$, specificity $100 \%$, a positive predictive value of $96 \%$ and a negative predictive value of $100 \%$. Rout et al. reported the accuracy of thyroid swelling to be $96.05 \% .{ }^{20}$ A similar study conducted by Mundasad et al. has reported the accuracy of FNAC to be $79.1 \%$ for thyroid malignancy. ${ }^{17}$

Hence, there is a significant disparity in thyroid FNAC statistics. This may be due to an insufficient number of cases, diagnostic categories used and different classifications systems used by the cytopathologists. Vast experience is needed in performing a proper aspiration to get adequate material. It is recommended to overcome this problem by on-site adequacy testing by pathologist. The limitation of this study includes less sample size and FNAC samples being taken by different operators having various levels of skill and experience.

\section{CONCLUSIONS}

The findings of this study and findings reported by several other similar studies show that FNAC is a sensitive and specific method for the diagnosis of thyroid lesions if the sample is adequate and is from a representative area. FNAC is minimally invasive and cost-effective with very few complications. It has helped to reduce unnecessary surgeries and hence has improved the overall quality of life of patients with thyroid pathologies. However, due to chances of false-negative results it is advised that even the patients with benign cytologic findings be kept in regular clinical follow-up.

To cite this article: Kunwar S, Bajracharya B, Karmacharya K, Shrestha AN. Diagnostic accuracy of fine needle aspiration cytology of thyroid pathologies. MJSBH. 2020;19(2):84-89.

Conflict of Interest: None declared

\section{REFERENCES}

1. Ahmad T, Naeem M, Ahmad S, Samad A, Nasir A. Fine needle aspiration cytology (FNAC) and neck swellings in the surgical outpatient. J Ayub Med Coll Abbottabad. 2008;20(3):30-2. PMID:19610510 
2. Sharma R, Verma N, Kaushal V, Sharma DR, Sharma D. Diagnostic accuracy of fine-needle aspiration cytology of thyroid gland lesions: A study of 200 cases in Himalayan belt. J Cancer Res; 2017;13(3):451. DOI: 10.4103/0973-1482.164702

3. Sharma C. Diagnostic accuracy of fine needle aspiration cytology of thyroid and evaluation of discordant cases. $\mathrm{J}$ Egypt Natl Canc Inst; 2015;27(3):147-53. DOI: https://doi.org/10.1016/j.jnci.2015.06.001

4. Spartalis ED, Karatzas T, Charalampoudis P, Vergadis C, Dimitroulis D. Neglected papillary thyroid carcinoma seven years after initial diagnosis. Case Rep Oncol Med. Hindawi; 2013;2013:148973. DOI: https://doi.org/ $10.1155 / 2013 / 148973$

5. Alwahaibi N, Alsalami J, Bai UR, Lakhtakia R. Accuracy of fine needle aspiration cytology of thyroid lesion with corresponding histopathology: A single institutional experience. Thyroid Res Pract. 2016;13(3):140. DOI: https:// doi.org/10.4103/0973-0354.193136

6. Alshaikh S, Harb Z, Aljufairi E, Almahari SA. Classification of thyroid fine-needle aspiration cytology into Bethesda categories: An institutional experience and review of the literature. Cytojournal. 2018;15. DOI: https:// doi.org/10.4103/cytojournal.cytojournal_32_17

7. Bilal A, Saleem M. Role of fine needle aspiration cytology [FNAC] in the diagnosis of thyroid swellings. J Postgrad Med Inst. 2004;18(2):196-201.

8. Yang J, Schnadig V, Logrono R, Wasserman PG. Fine-needle aspiration of thyroid nodules: a study of 4703 patients with histologic and clinical correlations. Cancer Cytopathol. 2007;111(5):306-15. DOI:https://doi.org/ 10.1002/cncr.22955

9. Mistry SG, Mani N, Murthy P. Investigating the value of fine needle aspiration cytology in thyroid cancer. J Cytol Acad Cytol. 2011;28(4):185. DOI: https://doi.org/10.4103/0970-9371.86345

10. Gupta M, Gupta S, Gupta VB. Correlation of fine needle aspiration cytology with histopathology in the diagnosis of solitary thyroid nodule. J Thyroid Res. 2010;2010. DOI: https://doi.org/10.4061/2010/379051

11. Kumar S, Usha, Ganesan M. FNAC Vs Histopathology in the Diagnosis of Thyroid Swellings. J Med Sci Clin Res. 2017;05(02):17425-31. DOI: https://doi.org/10.18535/jmscr/v5i2.35

12. Sinna EA, Ezzat N. Diagnostic accuracy of fine needle aspiration cytology in thyroid lesions. J Egypt Natl Canc Inst. 2012;24(2):63-70. DOI: https://doi.org/10.1016/j.jnci.2012.01.001

13. Kuru B, Gulcelik NE, Gulcelik MA, Dincer H. Predictive index for carcinoma of thyroid nodules and its integration with fine-needle aspiration cytology. Head Neck J Sci Spec Head Neck. 2009;31(7):856-66. DOI: https://doi.org/ 10.1002/hed.21049

14. Esmaili HA, Taghipour H. Fine-needle aspiration in the diagnosis of thyroid diseases: An appraisal in our institution. ISRN Pathol. 2012;2012. DOI: https://doi.org/10.5402/2012/912728

15. Zhu Y, Song Y, Xu G, Fan Z, Ren W. Causes of misdiagnoses by thyroid fine-needle aspiration cytology (FNAC): our experience and a systematic review. Diagn Pathol. 2020;15(1):1-8. DOI: https://doi.org/10.1186/ s13000-019-0924-Z

16. Muratli A, Erdogan N, Sevim S, Unal I, Akyuz S. Diagnostic efficacy and importance of fine-needle aspiration cytology of thyroid nodules. J Cytol Acad Cytol. 2014;31(2):73. DOI: https://doi.org/10.4103/0970-9371.138666

17. Mundasad B, Mcallister I, Pyper P, Carson J. Accuracy of fine needle aspiration cytology in diagnosis of thyroid swellings. Cytopathol Suppl. 2003;14.

18. Baloch ZW, LiVolsi VA, Asa SL, Rosai J, Merino MJ, Randolph G, et al. Diagnostic terminology and morphologic criteria for cytologic diagnosis of thyroid lesions: a synopsis of the National Cancer Institute Thyroid Fine-Needle Aspiration State of the Science Conference. Diagn Cytopathol. 2008;36(6):425-37. DOI: https://doi.org/10.1002/dc. 20830

19. Handa U, Garg S, Mohan H, Nagarkar N. Role of fine needle aspiration cytology in diagnosis and management of thyroid lesions: A study on 434 patients. J Cytol. 2008;25(1):13. DOI: https://doi.org/10.4103/0970-9371.40652

20. Rout K, Ray CS, Behera SK, Biswal R. A comparative study of FNAC and histopathology of thyroid swellings. Indian J Otolaryngol Head Neck Surg. 2011;63(4):370-2. DOI: https://doi.org/10.1007/s12070-011-0280-0 